\section{BMJ Paediatrics Open}

\title{
Perspectives of adolescents on decision making about participation in a biobank study: a pilot study
}

Petronella Grootens-Wiegers, ${ }^{1,2}$ Eline G Visser, ${ }^{3}$ Annemarie M C van Rossum, ${ }^{3}$ Claudia N van Waardhuizen, ${ }^{4,5,6}$ Saskia N de Wildt, ${ }^{7,8}$ Boudewijn Sweep, ${ }^{1}$ Jos $\mathrm{M}$ van den Broek, ${ }^{1}$ Martine $\mathrm{C}$ de Vries $^{9}$

To cite: Grootens-Wiegers $P$, Visser EG, van Rossum AMC, et al. Perspectives of adolescents on decision making about participation in a biobank study: a pilot study. BMJ Paediatrics Open 2017;1:e000111. doi:10.1136/ bmjpo-2017-000111

- Additional material is published online only. To view please visit the journal online (http://dx.doi.org/10.1136/ bmjpo-2017-000111).

Received 29 May 2017 Revised 27 July 2017 Accepted 28 July 2017

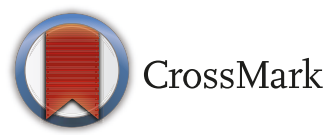

For numbered affiliations see end of article.

Correspondence to Dr Petronella Grootens-Wiegers; p.grootens@lumc.nl

\section{ABSTRACT}

Objectives To be able to truly involve adolescents in decision making about clinical research participation, we need more insight in the perspective of adolescents themselves. To this end, adolescents in an ongoing biobank study were consulted to test a tentative decision assessment tool.

Methods The perspectives of adolescents $(n=8)$ concerning participation in decision making for research participation were explored in interviews with a tentative tool, which covered six topics: information material usage, understanding, disease perceptions, anxiety, decisionmaking process and role sharing.

Results All adolescents unequivocally expressed the desire to be involved in decision making, but also wanted advice from their parents. The extent of the preferred role of adolescent versus parents varied between individuals. In decision making, adolescents relied on parents for information. More than half hardly used the information material.

Conclusions Adolescents in our study preferred a shared decision-making process. The extent of sharing varied between individuals. The decision assessment tool was a fruitful starting point to discuss adolescents' perspectives and may aid in tailoring the situation to the individual to achieve optimal participation practices.

Implications Consulting adolescents about their preferences concerning decision making using the tool will facilitate tailoring of the shared decision-making process and optimising the developing autonomy of minors.

\section{INTRODUCTION}

There is an increasing attention for participation of minors in matters that affect them in general, and more specifically to involve them in healthcare decision making. ${ }^{1-4}$ In spite of this attention, true implementation of participation in clinical practice, let alone research participation, is poor. ${ }^{5}$ Minors are often not heard, nor consulted about decisions that concern them. ${ }^{36-10}$ The discrepancy between the voiced awareness towards participation of minors and current practice is caused by (A) a lack of evidence-based insights

\section{What is already known on this topic?}

There is an increasing attention for participation of minors in healthcare decision making, among which decisions about participation in clinical research.

- Nevertheless, there is a lack of evidence-based insights guiding this participation of minors in practice.

- Research consulting minors on their experiences of the decision-making process and how they view their own role is scarce.

\section{What this study hopes to add?}

A tentative decision assessment tool successfully initiated insightful discussions with adolescents about their perspectives on their role in consenting for research.

- Adolescents relied on their parents for information instead of informing themselves.

- Adolescents preferred a shared decision-making approach together with their parents; the preferred extent of sharing varied between individuals.

guiding participation in practice, ${ }^{5}$ and (B) a lack of adequate age-adjusted information supporting healthcare decisions. ${ }^{11}$

Recent research suggests that minors from around the age of 12 are capable of being involved in decision making, but that this competence depends on facilitating situational factors. ${ }^{12-14}$ An essential situational factor is the attitude of healthcare professionals and parents or caretakers, but it is not yet clear which attitude is most facilitating and how to achieve optimal dynamics between involved adults and minors. ${ }^{15} 16$

In addition, the minor also plays an important role in these dynamics. However, studies on the role of adolescents in decision making often consult parents instead of minors, whereas parents are unreliable 
proxy reporters. ${ }^{17}$ Research consulting the people at stake-minors-is scarce. More evidence is needed to understand how they experience the decision-making process, to what extent they prefer to be involved and how they view their own role. ${ }^{417} 18$

A prerequisite for making an informed decision about clinical research participation is to understand what is at stake. ${ }^{11}{ }^{19}$ Various studies demonstrate that research information material for minors is not written at a comprehensible level. ${ }^{20-22}$ In addition, verbal information supply fails as doctor-patient conversations are commonly directed at parents or caretakers, rather than addressing the minor. ${ }^{1023}$ Without adequate information, a minor can impossibly use its full potential to participate nor to play a meaningful role in the decision-making process. $^{924-28}$

In order to advance the involvement of minors in decisions about clinical research participation, it is vital that they are empowered by comprehensible information, and that evidence-based insights are gained to guide participation practice. In this paper, a pilot study is presented in which we provide adolescents participating in a biobank study with previously developed novel information material, and study their perspectives on the decision-making process with the use of a 'decision assessment tool.' Our aim in this pilot study is (1) to gain insight in the experiences of adolescents involved in the decision-making process about research participation; (2) to perform an initial examination of the feasibility of a short interview tool on decision-making perspectives, which could be used in further research on perspectives of minors; and (3) to perform an initial assessment of the novel information material in clinical practice, and compare this material to the standard material.

\section{METHODS}

\section{Sample}

Participants were recruited between February and May 2016 from an ongoing study: the Sophia Biobank at the Erasmus MC Sophia in Rotterdam, the Netherlands. The Sophia Biobank is the first European-registered paediatric hospital biobank, collecting samples from healthy minors. Minors undergoing an elective surgery procedure but otherwise healthy given certain selection criteria are requested to donate blood, which is drawn from an intravenous catheter during anaesthetic preoperation procedures.

Adolescents in the age of 12-17 were selected for inclusion, which is the age category for official involvement in the informed consent process in the Netherlands. Adolescents eligible for the Sophia Biobank received written information material at home 2 weeks before the procedure. Subsequently, a research nurse called to ask about participation in the biobank and in a single extra interview about the decision-making process. Adolescents were then called by the researcher to make an interview appointment.

\section{Information material}

Participants received one of two types of a Research Information Form (RIF): a standard, textual RIF or a novel visual/textual RIF (see online supplementary appendix for examples and translations). Participants were randomised to receive one of the two RIF types by distribution in alternating weeks.

These RIFs were official legal documents, as in the Netherlands a double consent (parent+child) is mandatory for research participants aged 12 years or older. The standard RIF consisted of three pages of plain text, and one page for signing for informed consent.

The novel RIF consisted of a comic strip booklet explaining essential research concepts and an illustrated study-specific form which were previously developed together with end-users (minors, parents, paediatricians, research nurses) and positively evaluated. ${ }^{29}$

\section{Decision assessment tool}

A tentative decision assessment tool was developed based on combining interview studies from Tait $e t a l^{27}$ on understanding of research aspects, and Lipstein et $a \hat{l}^{30}$ consulting adolescents about treatment decisions. We aimed hereby to create a tool to consult adolescents about their understanding, their view on the decision-making process and their desired role in it. The resulting tool (see table 1) consisted of questions on (A) demographics; (B) evaluation of information material; (C) feeling of understanding and actual understanding, as in ref 27; (D) disease perceptions based on drawings, as in ref 31; (E) anxiety about surgery and research, on a scale from 1 (not anxious) to 10 (very anxious); and (F) questions evaluating the decision-making process, initiated by an exercise to draw a pie chart indicating the role sharing in the decision-making process, and a second pie chart with the preferred sharing for a future decision, as adapted from ref 30 .

\section{Data collection and analysis}

The interviews were conducted by a student researcher, either at the adolescent's home or at the hospital cafeteria, depending on the adolescent's preference. Adolescents and parents signed a concise consent form prior to the interview. A parent (in one case both parents) accompanied the participant during all interviews, but questions were directed at the adolescent. The adolescent was also made explicitly aware that answering questions was voluntary. The interviews took approximately $20 \mathrm{~min}$ and were audio-recorded and transcribed verbatim. Transcripts were analysed with QDA Miner 4 Lite using the thematic framework approach. ${ }^{32}$ The first researcher (PGW) identified initial themes and applied these on two interviews. Authors PGW and BS discussed the framework and themes until consensus was reached. Subsequently, author PGW labelled all interviews and identified the main themes: 'information use', 'decision-making process' and 'perspectives on decision-making role'. 
Table 1 Decision assessment tool-description of the various elements of the tentative decision tool

\begin{tabular}{|c|c|}
\hline Element & Description \\
\hline $\begin{array}{l}\text { Part 1-demographics and } \\
\text { background }\end{array}$ & $\begin{array}{l}\text { Demographics } \\
\text { Questions regarding having read the information material; understanding and appreciation of } \\
\text { the material; previous hospital experiences }\end{array}$ \\
\hline Part 2-disease perception & $\begin{array}{l}\text { Drawing reason for surgery as in ref } 31 \\
\text { Indicate on a scale of } 1-10 \text { the severity of the reason for surgery }\end{array}$ \\
\hline Part 3-understanding & Feeling of understanding and actual understanding, adapted from ref 27 \\
\hline Part 4-anxiety & $\begin{array}{l}\text { Adapted from ref } 27 \text {; indicate on a scale of } 1-10 \text { anxiety for surgery; indicate on a scale of } \\
1-10 \text { whether research participation has influenced anxiety }\end{array}$ \\
\hline $\begin{array}{l}\text { Part } 5 \text {-interest, satisfaction } \\
\text { and role sharing }\end{array}$ & $\begin{array}{l}\text { Adapted from ref } 30 \text {; exercise to draw a pie chart indicating the role sharing in the decision- } \\
\text { making process, and a second pie chart with the preferred sharing for a future decision; } \\
\text { interview questions to elaborate during drawing } \\
\text { Further questions regarding which information was used for the decision and which aspects } \\
\text { were considered in making the decision }\end{array}$ \\
\hline
\end{tabular}

\section{RESULTS}

\section{Inclusion}

A total of 10 adolescents (aged 12-17) of the 19 Sophia Biobank participants in the timespan of our study agreed to participate, all were native Dutch speakers. Of these, eight were included; two reported to have second thoughts and withdrew. Six had received the novel RIF and two the standard RIF. We aimed to interview the adolescents before surgery, but due to time constraints some were interviewed afterwards. One adolescent consented to participate in the Sophia Biobank, but blood drawing failed due to medical reasons; this adolescent was still included as the decision making happened beforehand.

\section{Anxiety}

All participants indicated to be somewhat anxious for the surgery, ranging from 5 to 8 on a scale from 1 (not anxious) to 10 (very anxious). One was not anxious at all and explained he had already had three previous surgeries. All expressed that research participation did not influence their anxiety for surgery.

\section{Disease perceptions}

Participants were asked to make free drawings about the reason for surgery. All but one made a simplified drawing of the human body or a part of it, showing a defect, for example, crossed eyes. When asked to elaborate, they talked about a single defect that was mildly interfering with their life. One participant created a more interpretative drawing, showing a person with a large birthmark and another shouting harassing words, explaining that the surgery was for aesthetic and personal reasons.

\section{Understanding}

Participants declared to have good understanding of the biobank study (scored on a scale of 1 -poor to 10-good): goal (mean 8.3), procedure (mean 8.4), personal benefit (mean 7.0), benefit for others (mean 8.4), alternative to participation (mean 7.4 ) and voluntary participation (mean 8.9). Understanding of the right to withdraw was poor in half of the participants (total mean 5.8). Subsequent open questions to elaborate on these concepts revealed that the participants indeed had a good understanding of most aspects, except some were unsure how exactly others would benefit, three were confused by the right to withdraw, and all but one were unable to describe the research goal.

\section{Decision-making process}

All participants described the process of decision making as short and straightforward. Most recalled to have received information material by mail, which they either read or merely looked at, and then shortly discussed the research with their parents. They then had a short conversation with the research nurse and signed the consent form. Participants mentioned that the decision was not hard, it was 'only donating blood.' They did not mention any disadvantages of participation, or explicitly mentioned that there were only advantages: 'helping other children' and 'for science'; 'you can make other children well and you do not suffer from it at all'.

\section{Information use}

All participants except one had seen the information material, but only two had thoroughly read it before surgery, and one had read it afterwards. The other five had either only looked at the pictures in the novel material $(n=3)$ or read half of the standard RIF $(n=2)$. None of the participants described in-depth discussions about participation, or the need to gain more information to reach a conclusion, or as one participant said: 'I think the story was just clear what it was about [...] so I did not need to ask things or to discuss things.'

All participants were moderately satisfied with the information material and indicated that the information was easy to read and understand and was mildly interesting. Unfortunately, we were unable to make a comparison between the standard and novel RIFs, because of the small sample size and resulting uneven distribution of RIFs. 

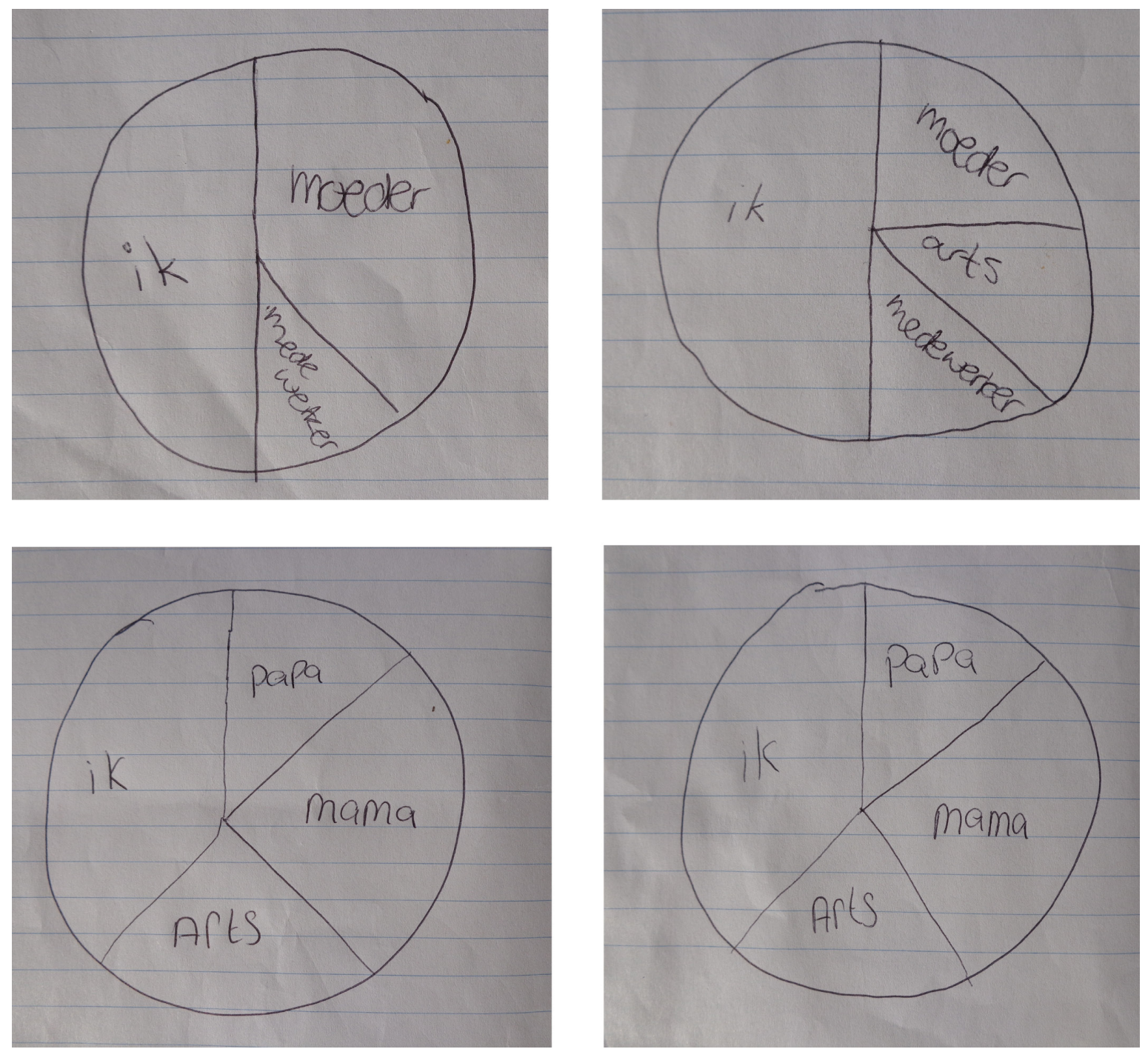

Figure 1 Examples of the pie charts from two participants, describing the current role sharing (left) and the desired role sharing (right) for a future decision (translation: ik=l; moeder=mother; medewerker=employee; arts=doctor).

\section{Perspective on decision-making role}

All adolescents reported to have been involved in decision making, ranging in size of the share from $20 \%$ to $80 \%$ (see figure 1 for an example). Also, either the mother or both parents played a role, ranging in size from $20 \%$ to $80 \%$. Two adolescents recognised the doctor as a party, and one the research nurse, based on receiving explanations, ranging from $10 \%$ to $30 \%$.

Only three participants shared preferred roles for a future decision differently: two assigned a greater share to the doctor and/or research nurse, and one wished to discuss with a friend and ask for her advice.

All adolescents expressed unequivocally that they wanted to be involved in decision making about research participation, responding: 'When it is about your own body, I do want to decide it for myself'; and 'I am the one who needs to donate the blood'. However, the word 'we' was also frequently used in participants' accounts, demonstrating that the adolescents did not decide on their own, but rather that the process was experienced as shared decision making. One stated 'I think that she [mother] can make a good decision... she knows everything about me.' Another participant summarised 'It was my own decision and that of someone else [...] in fact, $100 \%$ of the three of us.'

\section{Feasibility of using the decision assessment tool}

The questions and exercises in the decision assessment tool helped initiate a conversation in which the adolescents expressed their personal opinions and thoughts. The use of a pie chart exercise was suitable for this age group, when the concept was explained carefully. The pie charts appeared to be a fruitful starting point to discuss the roles of adolescents in the decision.

\section{DISCUSSION AND CONCLUSION}

\section{Discussion}

Adolescents were consulted about their perspectives on their role in decision making for clinical research participation, with a tentative decision assessment tool. 
Participants reported they did not feel the need to be thoroughly informed, because it was not a complex decision to make, which is consistent with the experience of the involved research nurse of the Sophia Biobank. Although other studies report that minors express the desire to be informed, ${ }^{33}$ this was not confirmed by our study. It is possible that adolescents participating in more invasive or longitudinal studies feel more personally involved and more motivated to be well informed. Alternatively, adolescents in general might not care much for written information, but rather rely on adults to inform them, as reported elsewhere. ${ }^{34}$ In that case, the reported misunderstandings among minors might partly originate from poorly informed parents, or even due to low quality of information material for parents. ${ }^{35}$

Participants experienced the decision making as straightforward and reported that the lack of burden and the potential to help others made them decide to participate without further consideration. All adolescents had participated in the decision about participation in the Sophia Biobank research and expressed the desire to be involved in decision making about their own body. In addition, all of them mentioned the need for advice from their parents and sometimes their doctor. This is consistent with a recent study reporting that children relied on their parents to share information and interpret it. ${ }^{34}$

The extent to which adolescents wished to be involved in the decision-making process varied per person and per the family dynamics, as has been reported before. ${ }^{396}$ Participation of adolescents is thus not an on-or-off phenomenon, but rather varies per specific situation. Using the tentative decision assessment tool, we were able to gain insight in the opinions, experiences and preferences of adolescents. The tool could be useful in further studies on the perspectives of adolescents, but more research is required and the tool needs further testing on validity and reliability. In addition, the tool, or a part of it such as the pie chart exercise, might be used in clinical practice in order to tailor the informed consent process.

\section{Limitations}

This study has several limitations impairing generalisability. First, the sample size was small, because of the set-up of this pilot study with a limited time period. Therefore, we were unable to compare the two types of RIFs. Only participants who did participate in the Sophia Biobank were included, possibly leading to a bias. Also, a parent was always present during interviews, possibly interfering with the adolescent's perceived freedom to speak freely. In addition, the decision assessment tool was used without validation, as this pilot study was an initial exploration. Further research to validate and optimise the tool is necessary.

\section{Conclusion}

The quality of the written information material did not play a major role in the decision making of adolescents to participate in a biobank study. Minors preferred a shared decision-making approach in which they rely on their parents for information and advice, with preferred sharing varying between individuals. The proposed decision assessment tool may be used to guide optimal participation in research practice and could also be used to further study optimal ways to stimulate participation.

\section{Author affiliations}

${ }^{1}$ Department of Science Communication and Society, Leiden University, Leiden, The Netherlands

${ }^{2}$ Committee of Medical Ethics, Leiden University Medical Center, Leiden, The Netherlands

${ }^{3}$ Department of Pediatrics, Division of Infectious Diseases and Immunology, Erasmus MC University Medical Center, Rotterdam, The Netherlands

${ }^{4}$ Theme Sophia, Sector Research Office-Theme Sophia Biobank, Erasmus MC University Medical Center, Rotterdam, The Netherlands

${ }^{5}$ Department of Epidemiology, Erasmus MC University Medical Center, Rotterdam, The Netherlands

${ }^{6}$ Department of Radiology, Erasmus MC University Medical Center, Rotterdam, The Netherlands

${ }^{7}$ Intensive Care and Department of Pediatric Surgery, Erasmus MC University Medical Center, Leiden, The Netherlands

${ }^{8}$ Department of Pharmacology and Toxicology, Radboud University, Nijmegen, The Netherlands

${ }^{9}$ Departments of Pediatrics and Ethics and Health Law, Leiden University Medical Center, Nijmegen, The Netherlands

Acknowledgements The authors would like to thank Irene Cécile for her important role in developing the novel information material. We would also like to thank the research nurse Marianne Maliepaard for her assistance in the recruiting process.

Contributors PGW designed the concept of this research and conducted the research, drafted the manuscript and contributed to critical revisions, and shares the accountability for this manuscript. EGV, AMCvR, CNvW and SNdW were involved in the essential design stages of this research and contributed to critical revisions, and approved and share the accountability for this manuscript. BS conducted the research and contributed to critical revisions, and approved and shares the accountability for this manuscript. JMvdB acted as a supervisor of the research and was involved in the draft concept and revisions of the manuscript, and approved and shares the accountability for this manuscript. MCdV acted as a supervisor on the research, helped design the project, provided extensive feedback on the line of reasoning of the draft versions, and approved and shares the accountability for this manuscript.

Funding This work was supported by The Netherlands Organisation for Health Research and Development (Project No. 113203016).

Competing interests None declared.

Patient consent Obtained.

Ethics approval Medical Ethics Committee of Erasmus University Medical Center. Provenance and peer review Not commissioned; externally peer reviewed. Data sharing statement No additional data available.

Open Access This is an Open Access article distributed in accordance with the Creative Commons Attribution Non Commercial (CC BY-NC 4.0) license, which permits others to distribute, remix, adapt, build upon this work non-commercially, and license their derivative works on different terms, provided the original work is properly cited and the use is non-commercial. See: http://creativecommons.org/ licenses/by-nc/4.0/

C Article author(s) (or their employer(s) unless otherwise stated in the text of the article) 2017. All rights reserved. No commercial use is permitted unless otherwise expressly granted.

\section{REFERENCES}

1. Committee on Bioethics. Informed consent, parental permission, and assent in pediatric practice. Pediatrics 1995;95:314-7. 
2. Unicef. Convention on the Rights of the Child: United Nations Treaty Collection, 1989:1577.3.

3. Coyne I, Harder M. Children's participation in decision-making: balancing protection with shared decision-making using a situational perspective. J Child Health Care 2011;15:312-9.

4. Clavering EK, McLaughlin J. Children's participation in health research: from objects to agents? Child Care Health Dev 2010;36:603-11.

5. Weil LG, Lemer C, Webb E, et al. The voices of children and young people in health: where are we now? Arch Dis Child 2015;100:915-7.

6. de Vries MC. The use of dogmas in pediatric research ethics. Am J Bioeth 2015;15:18-19.

7. Dedding $C$, Reis R, Wolf B, et al. Revealing the hidden agency of children in a clinical setting. Health Expect 2015;18:2121-8.

8. Virkki M, Tolonen TH, Koskimaa T, et al. Children as decision-makers in health care - An integrative review. Clin Nurs Stud 2014;3:47.

9. Coyne I, Gallagher P. Participation in communication and decisionmaking: children and young people's experiences in a hospital setting. J Clin Nurs 2011;20:2334-43.

10. Tates K, Meeuwesen L, Bensing J, et al. Joking or decisionmaking? affective and instrumental behaviour in doctor-parent-child communication. Psychol Health 2002;17:281-95.

11. Appelbaum PS, Grisso T. The MacArthur Competence Assessment Tool for Clinical Research (MacCAT-CR). Sarasota, FL: Professional Resource Press, 2011.

12. Hein IM, Troost PW, Lindeboom R, et al. Key factors in children's competence to consent to clinical research. BMC Med Ethics 2015;16:74.

13. Hein IM, Troost PW, Broersma A, et al. Why is it hard to make progress in assessing children's decision-making competence? BMC Med Ethics 2015;16:1.

14. Hein IM, Troost PW, Lindeboom R, et al. Accuracy of the MacArthur Competence Assessment Tool for Clinical Research (MacCAT-CR) for measuring children's competence to consent to clinical research. JAMA Pediatr 2014;168:1147-53.

15. Mårtenson EK, Fägerskiöld AM. A review of children's decisionmaking competence in health care. J Clin Nurs 2008;17:3131-41.

16. Young AJ, Kim L, Shu Li, et al. Agency and communication challenges in discussions of informed consent in pediatric cancer research. Qual Health Res 2010;20:628-43.

17. Lipstein EA, Brinkman WB, Fiks AG, et al. An emerging field of research: challenges in pediatric decision making. Med Decis Making 2015;35:403-8.

18. Ruhe KM, Wangmo T, Badarau DO, et al. Decision-making capacity of children and adolescents-suggestions for advancing the concept's implementation in pediatric healthcare. Eur J Pediatr 2015;174:775-82

19. de Vries MC, Wit JM, Engberts DP, et al. Pediatric oncologists' attitudes towards involving adolescents in decision-making concerning research participation. Pediatr Blood Cancer 2010;55:123-8.
20. Grootens-Wiegers P, De Vries MC, Vossen TE, et al. Readability and visuals in medical research information forms for children and adolescents. Sci Commun 2015;37:89-117.

21. Ménoni V, Lucas N, Leforestier JF, et al. Readability of the written study information in pediatric research in France. PLoS One 2011;6:e18484

22. Tarnowski KJ, Allen DM, Mayhall C, et al. Readability of pediatric biomedical research informed consent forms. Pediatrics 1990;85:58-62.

23. Tates K, Meeuwesen L, Elbers E, et al. I've come for his throat': roles and identities in doctor-parent-child communication. Child Care Health Dev 2002;28:109-16.

24. Kuther TL, Posada M. Children and adolescents' capacity to provide informed consent for participation in research. Adv Psychol Res 2004;32:163-73.

25. Unguru Y, Sill AM, Kamani N. The experiences of children enrolled in pediatric oncology research: implications for assent. Pediatrics 2010;125:e876-83.

26. O'Lonergan TA, Forster-Harwood JE. Novel approach to parental permission and child assent for research: improving comprehension. Pediatrics 2011:127:917-24.

27. Tait AR, Voepel-Lewis T, Malviya S, understand Dthey. Do they understand? (part II): assent of children participating in clinical anesthesia and surgery research. Anesthesiology 2003;98:609-14.

28. Tait AR, Voepel-Lewis T, Malviya S. Presenting research information to children: a tale of two methods. Anesth Analg 2007:105:358-64.

29. Grootens-Wiegers P, de Vries MC, van Beusekom MM, et al. Comic strips help children understand medical research: targeting the informed consent procedure to children's needs. Patient Educ Couns 2015;98:518-24.

30. Lipstein EA, Muething KA, Dodds CM, et al. 'I'm the one taking it': adolescent participation in chronic disease treatment decisions. $J$ Adolesc Health 2013;53:253-9.

31. Broadbent E, Ellis CJ, Gamble G, et al. Changes in patient drawings of the heart identify slow recovery after myocardial infarction. Psychosom Med 2006;68:910-3.

32. Ritchie J, Spencer L, O'Connor W. Carrying out qualitative analysis. In: Lewis J, Ritchie J, Qualitative research in practice. London: SAGE Publications, 2003:219-62.

33. van der Pal S, Sozanska B, Madden D, et al. Opinions of children about participation in medical genetic research. Public Health Genomics 2011:14:271-8.

34. Coyne I, Amory A, Gibson F, et al. Information-sharing between healthcare professionals, parents and children with cancer: more than a matter of information exchange. Eur $\mathrm{J}$ Cancer Care 2016;25:141-56.

35. Kass NE, Chaisson L, Taylor HA, et al. Length and complexity of US and international HIV consent forms from federal HIV network trials. $J$ Gen Intern Med 2011;26:1324-8.

36. Snethen JA, Broome ME, Knafl K, et al. Family patterns of decisionmaking in pediatric clinical trials. Res Nurs Health 2006;29:223-32. 